\title{
Self Organizing Feature Map Network for Musical Instrument Sounds
}

\author{
Gulhane Sushen R., Shirbahadurkar Suresh D., Badhe Sanjay S
}

\begin{abstract}
Self Organizing Feature Map Network is used as a classifier for classification of features extracted of the sound database of Musical Instruments. However, the database of Indian Classical Musical Instruments is prepared for 15 instruments. The different types of features such as Temporal, Spectral and Cepstral features are available out of which we have considered Spectral features i.e. Roll off, Centroid, RMS Energy, Zero Crossing Rate, Spectral Irregularity \& Spectral Brightness.
\end{abstract}

Keywords - Roll off, Centroid, RMS Energy, Zero Crossing Rate, Spectral Irregularity \& Brightness.

\section{INTRODUCTION}

The cultural activity whose medium is sound organized in time, terms as Music. There are no. of important elements of Music out of which Timbre, Rhythm, Pitch are considered mostly. Timbre is element which shows the color of sound. The different types of music may emphasize, de-emphasize or omit some of these elements.

As we know, every god is associated with Musical Instrument such as Saraswati with Veen, Shiva with Damaru, etc. There are lot of Musical instrument using from ancient times out of which some were going to be used for the conveying the messages. During war also, some instruments were going to be used for giving message. In Ramayana and Mahabharata, Drums were used to convey message of peace [30].

In India, there are no. of caves, temples and at these places it has been found that there are no. musical instruments in the sculpture existing. From the early decade, it has understood the salutary use of musical instruments. Musical Instrument are manufactured using different types of materials. The materials such as skin, cotton thread, wood, clay. Tata Vadya, Sushir Vadya, and Avanaddha Vadya \& Ghana Vadya are the different types of musical instruments classified according to the material used [30].

Revised Manuscript Received on July 25, 2019.

Mr. Gulhane Sushen R., Research Scholar ( DYPIT), DYPCOE (SPPU), Pune, India, sushenrgulhane1 @ rediffmail.com

Dr. Shirbahadurkar Suresh D., Research Guide ( DYPIT), Zeal COE (SPPU), Pune, India, shirsd112@yahoo.com

Mr. Badhe Sanjay S., Research Scholar (DYPIT), DYPCOE (SPPU), Pune, India, sanjubadhe@gmail.com
Feature Extraction is termed as the way of extracting the features of signal. They are temporal features, Spectral Features, and Cepstral features. The Spectral features are extracted from the musical instrument sound signals.

In this paper, Spectral (timbral) features of Musical Instrument Sounds are extracted using Music Information Retrieval (MIR) toolbox 1.6. After extracting the features, they are analyzed and used for further classification of Musical Instrument for Identification.

For database generation of Musical Instrument Sounds, 15 Musical Instruments are considered. Out of which, 4 Indian Woodwind Musical Instruments, 3 Western Woodwind Musical Instruments, 5 Indian String Musical Instruments, and 3 Western String Musical Instruments and each have 15 samples. So in all 225 samples database is created.

\section{THEORY}

Artificial Neural Network is a boom technology now a days. ANN is a network of group of nodes wherein they are interconnected. There are no. of types of ANN out of which Self organizing feature map is a network which is trained using unsupervised learning technique. It produces a lowdimensional, discretized representation of the input space of the training samples, called a map, and is, therefore, a method to do dimensionality reduction [29]. SOFM uses competitive learning instead of error-correction learning. It uses neighborhood function to restore the similar properties of the input space due to which it differs from other artificial neural networks [29].

Self Organizing Map neural network model need no human interaction or supervision during the training due to which it comes under unsupervised learning and hence it is considered as the most popular neural network model and it needs something to be known about the features of the input data [29]. We could, for example, without knowing the class membership of the input data sample, SOM has been used for congregating the data samples. SOM can be deployed to discover the features immanent to the problem and due to which it has also been known as the Self-Organizing Feature Map(SOMF).

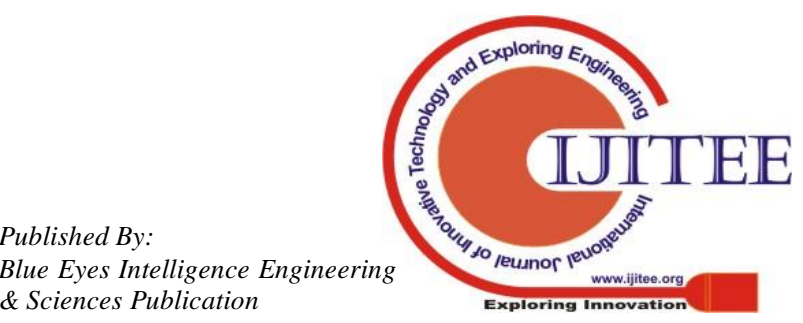


Self Organizing Map algorithm is based on unsupervised, competitive learning. The SOM can thus present as a group analyzing tool of huge-dimensional data. Also, the SOM has the capability to generalize [29].

A number of classifiers are available for classification. Here, we have used SOMF Classifier for the Musical Instrument Classifier.

Musical instrument Identification is the way to identify the musical instrument to which belongs. For identification of Musical Instrument System following is the block diagram.

\section{A. Block Diagram:}

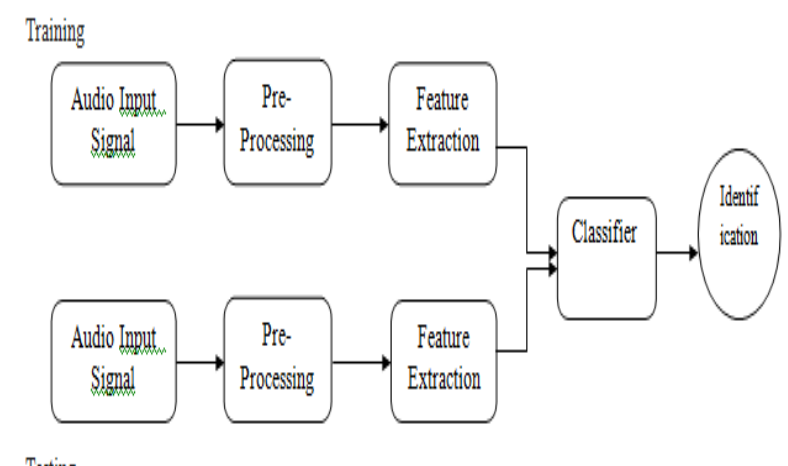

Testing

Fig 1: Block Diagram of Musical Instrument Identification

Here, Audio Input signal is provided to the Pre-processing stage. Then features are extracted and fed to Classifier. Similarly, the same steps are to be performed for the testing phase. Then both phases' inputs are to be given classifier. The classifier will compare the inputs and according classify/identify the instruments.

\section{EXPERIMENT RESULTS}

The number of experiments is performed for feature extraction of audio signals. For experimentation, audio input is taken. In the proposed system, audio timbral features are extracted of the sound samples.

\section{Timbral feature extractors}

The experiments are performed for extracting the timbral features. The results are shown below: Here results have shown in Table 1 of only eight instruments. The features for all 15 instruments are extracted and are used for classification.

\begin{tabular}{|c|c|c|c|c|c|c|c|c|}
\hline \multicolumn{9}{|c|}{$\begin{array}{c}\text { Table 1: Comparison of Timbral Features of Various } \\
\text { Instruments(Mean) }\end{array}$} \\
\hline $\begin{array}{c}\text { Type } \\
\text { of } \\
\text { Instru } \\
.\end{array}$ & nstruent & $Z C R$ & Roll off & $\begin{array}{c}\text { Bright } \\
\text { ness }\end{array}$ & $\begin{array}{c}\text { Roug } \\
\text { h } \\
\text { ness }\end{array}$ & $\begin{array}{l}\text { Irreg } \\
\text { ularity }\end{array}$ & $\begin{array}{l}\text { Rms } \\
\text { Enge } \\
\text { rgy }\end{array}$ & $\begin{array}{l}\text { Cent } \\
\text { roid }\end{array}$ \\
\hline \multirow{2}{*}{$\begin{array}{l}\text { Indian } \\
\text { Wood } \\
\text { wind }\end{array}$} & Flute & 0.00008 & 2.2564 & 0.0003 & 0.0000 & 0.0005 & 0.0001 & 1.2135 \\
\hline & Shehanai & 0.00041 & 4.2966 & 0.0009 & 0.0007 & 0.0007 & 0.0001 & 2.9422 \\
\hline \multirow{2}{*}{$\begin{array}{l}\text { West } \\
\text { wood } \\
\text { wind }\end{array}$} & Piccolo & 0.00017 & 3.0422 & 0.0004 & 0 & 0.0016 & 0.0000 & 1.6670 \\
\hline & $\begin{array}{l}\text { Sexo } \\
\text { phone }\end{array}$ & 0.00017 & 3.0577 & 0.0006 & 0 & 0.0007 & 0 & 1.8483 \\
\hline
\end{tabular}
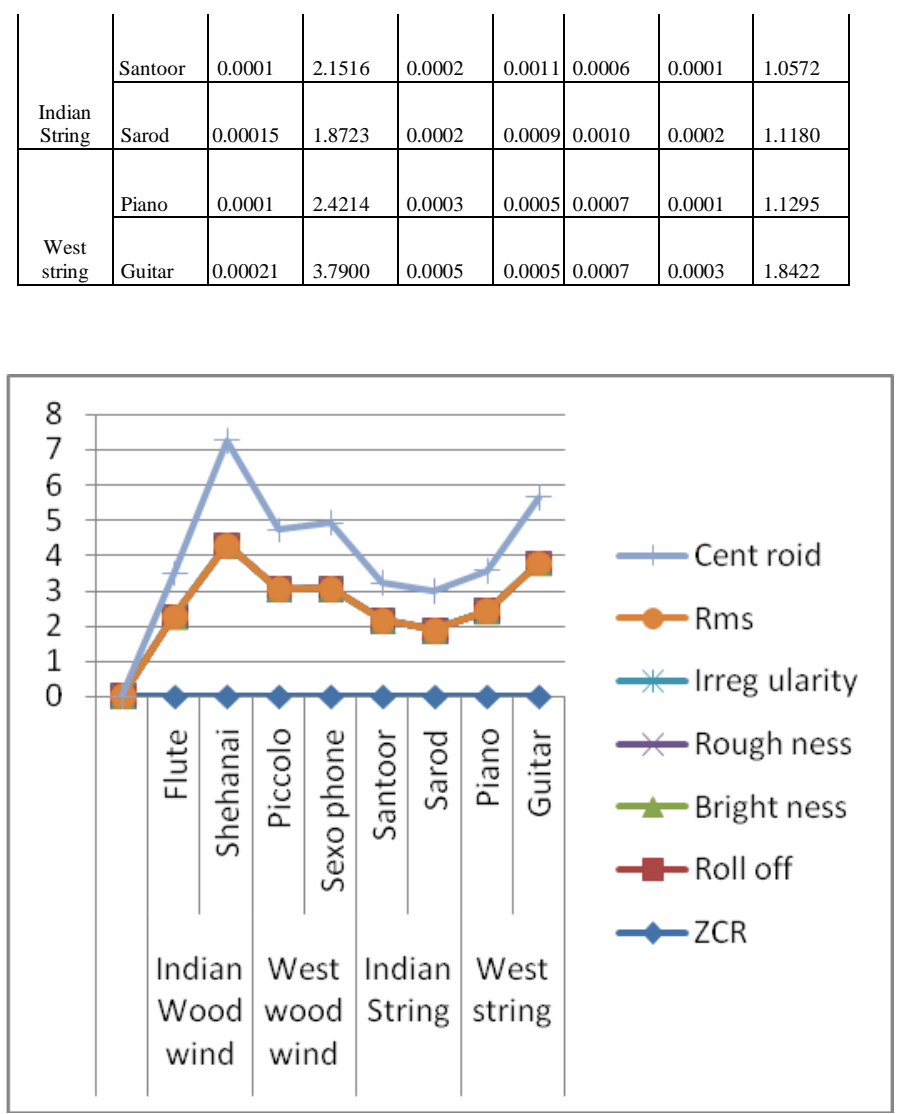

Graph 1: Comparison of Timbral Features of Various Instruments(Mean)

Graph 1 shows the comparison of different 'timbral features of Various Musical Instruments which is drawn from Table1.

Here, after extracting the features, the Self Organizing Feature Map Network is used for classification. In this out of $100 \%$ created database, $60 \%$ database is used for training, $40 \%$ database is used for testing and $15 \%$ database is used for cross-validation. The results are as follows:

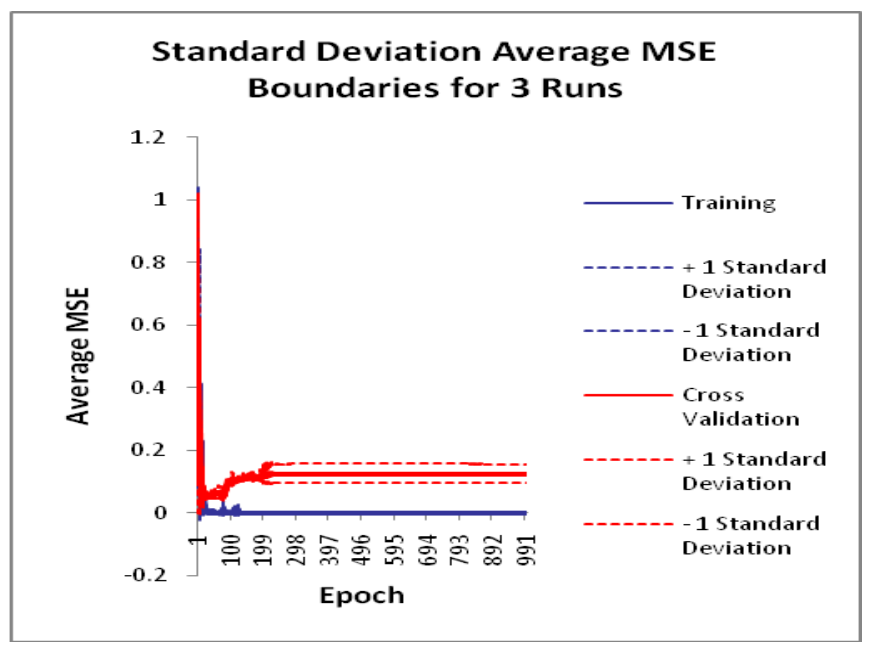

Graph 2: Std. Deviation Avg. MSE Boundaries

Here, Graph 2 shows the Avg. MSE parameter with std.

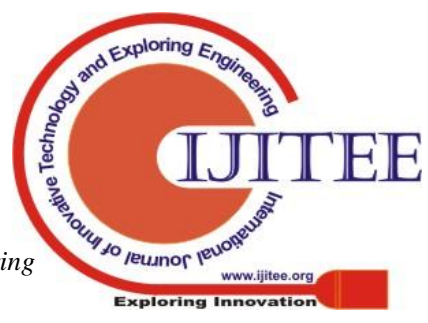


deviation boundaries for 3 iterations for training and Crossvalidation.

\begin{tabular}{|c|c|c|c|c|}
\hline \multicolumn{5}{|c|}{ Table 2: Avg. Minimum \& Avg. of Final MSEs of Training } \\
\hline All Runs & $\begin{array}{c}\text { Training. } \\
\text { Min }\end{array}$ & $\begin{array}{c}\text { Training } \\
\text { Std. Dev. }\end{array}$ & $\begin{array}{c}\text { Cross } \\
\text { Validation } \\
\text { Min. }\end{array}$ & $\begin{array}{c}\text { Cross } \\
\text { Validation } \\
\text { Std. Dev. }\end{array}$ \\
\hline $\begin{array}{c}\text { Avg. of Min. } \\
\text { MSEs }\end{array}$ & $\begin{array}{c}0.0001845 \\
68\end{array}$ & $\begin{array}{c}4.65045 \mathrm{E}- \\
05\end{array}$ & $\begin{array}{c}0.0402969 \\
47\end{array}$ & $\begin{array}{c}0.0035645 \\
77\end{array}$ \\
\hline $\begin{array}{c}\text { Avg. of } \\
\text { Final MSEs }\end{array}$ & $\begin{array}{c}0.0001845 \\
71\end{array}$ & $\begin{array}{c}4.64996 \mathrm{E}- \\
05\end{array}$ & $\begin{array}{c}0.1247007 \\
93\end{array}$ & $\begin{array}{c}0.0304680 \\
22\end{array}$ \\
\hline
\end{tabular}

Here, Table 2 shows the result of Avg. Min. and Avg. of Final MSE of Training \& Cross-Validation.

\begin{tabular}{|c|c|c|}
\hline \multicolumn{3}{|c|}{$\begin{array}{c}\text { Table 3: Training \& Cross Validation Data with Iterations \& } \\
\text { Epochs }\end{array}$} \\
\hline Best N/w.s & Training & Cross Validation \\
\hline Iteration \# & 1 & 3 \\
\hline Epoch \# & 998 & 20 \\
\hline Min. MSE & 0.000130869 & 0.036477847 \\
\hline Final MSE & 0.000130878 & 0.104271808 \\
\hline
\end{tabular}

Here, Table 3 shows the result of Training \& CrossValidation Data with Iterations \& Epochs

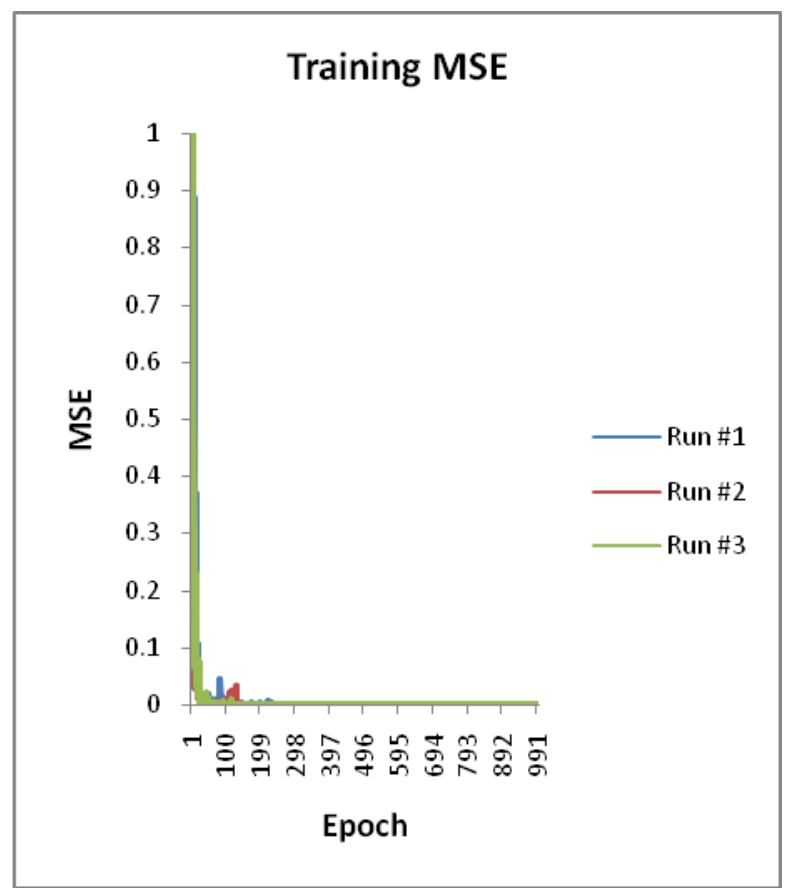

Graph 3: Training MSE

Here, Graph 3 shows the result of Training MSE with three Runs for 1000 epochs.

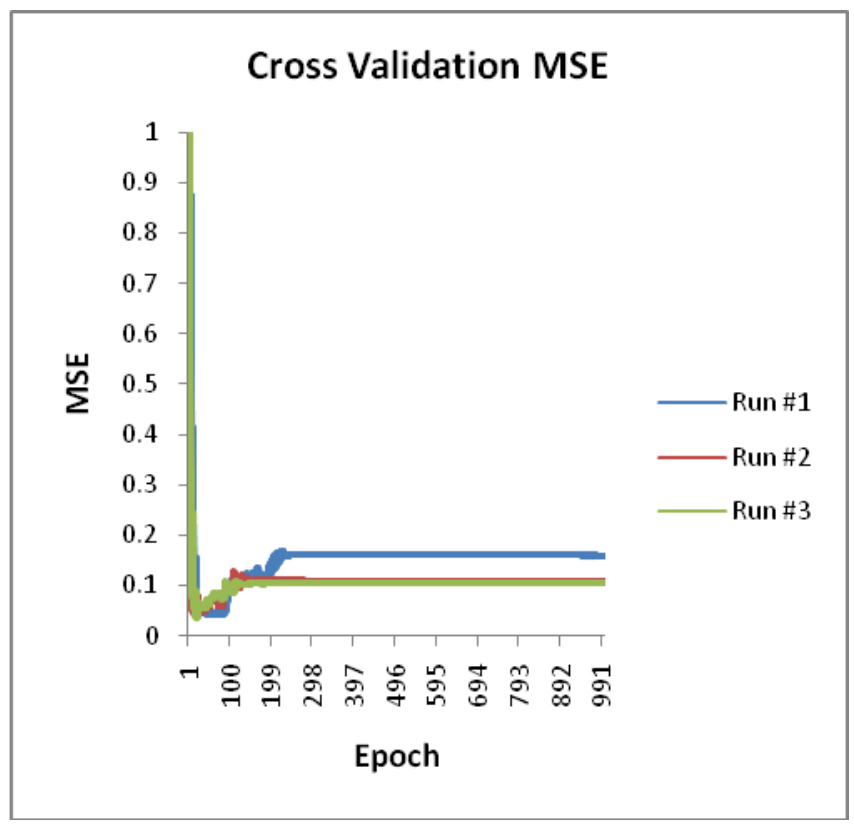

Graph 4: Showing Cross-Validation MSE

Here, Graph 4 shows the result of Cross-Validation MSE with three Runs for 1000 epochs.

The following table 4 shows the result is as shown;

\begin{tabular}{|c|c|c|c|}
\hline \multicolumn{4}{|c|}{ Table 4: Result of MII using SOFM Network } \\
\hline \multirow{2}{*}{$\begin{array}{c}\text { Statistical } \\
\text { Analysis }\end{array}$} & \multicolumn{3}{|c|}{ Self Organizing Feature Map Network } \\
\hline & Training & Testing & $\begin{array}{c}\text { Cross- } \\
\text { Validation }\end{array}$ \\
\hline MSE & 0.017533313 & 0.014402717 & 0.022517189 \\
\hline NMSE & 0.290747859 & 0.25610934 & 0.352838952 \\
\hline MAE & 0.060287812 & 0.061996583 & 0.071996975 \\
\hline $\begin{array}{c}\text { Min Abs } \\
\text { Error }\end{array}$ & 0.001976062 & 0.001051081 & 0.002316751 \\
\hline $\begin{array}{c}\text { Max Abs } \\
\text { Error }\end{array}$ & 0.530555095 & 0.587123778 & 0.49674898 \\
\hline $\mathrm{r}$ & 0.824768936 & 0.864429812 & 0.810862319 \\
\hline $\begin{array}{c}\text { Percent } \\
\text { Accuracy }\end{array}$ & 84.78771044 & 89 & 82 \\
\hline
\end{tabular}

Table 4 shows the results of musical instrument identification using Self Organizing Feature Map Network with parameters as MSE, NMSE, MAE, $r$ and Percentage Accuracy for Training, Testing and Cross-Validation phases.

\section{CONCLUSIONS:}

Numbers of experiments are performed to extract Timbral features which are required to identify the musical instruments \& analyzed and performed experimentation using Self Organizing Feature Map Network as classifier and concluded that SOFM Network gives $89 \%$ accuracy for Testing with $82 \%$ accuracy for Cross-Validation. 


\section{FUTURE SCOPE:}

The above techniques can be used for image identification as well as image features extraction.

\section{ACKNOWLEDGMENT}

I express my deep sense of gratitude to Dr. A.V. Kulkarni, Dean, R\&D, DYPIT, Pimpri \& Dr. S.M. Mali, Principal, DYPIT, Pimpri for their constant support.

I am very much thankful to all my friends for their direct and indirect support \& suggestions. Last but not least I am grateful to my family for motivating and supporting at different stages of my research work.

\section{REFERENCES}

[1] G. Eason, B. Noble, and I. N. Sneddon, "On certain integrals of Lipschitz-Hankel type involving products of Bessel functions," Phil. Trans. Roy. Soc. London, vol. A247, pp. 529551, April 1955. (references)

[2] D. Giannoulis and A. Klapuri, "Musical Instrument Recognition in Polyphonic Audio Using Missing Feature Approach," IEEE TRANSACTIONS ON AUDIO, SPEECH, AND LANGUAGE PROCESSING, Vols. VOL. 21, NO. 9, SEPTEMBER SEPTEMBER 2013

[3] S. Essid and G. Richard, "Musical Instrument Recognition by Pairwise Classification Strategies," IEEE TRANSACTIONS ON AUDIO, SPEECH, AND LANGUAGE PROCESSING, Vols. VOL. 14, NO. 4, JULY 2006.

[4] T. H. Park, "Towards Automatic Musical Instrument Timbre Recognition," Princeton University, New Jersey, USA, November 2004.

[5] O. Lartillot and P. Toiviainen, "A Matlab Toolbox for Musical Feature Extraction from Audio," in International Conference on Digital Audio Effects, Bordeaux, France, 2007.

[6] S. H. Deshmukh and S. G. Bhirud, "North Indian Classical Music's Singer Identification by Timbre Recognition using MIR Toolbox, "International Journal of Computer Applications, vol. 91 - No.4, p. 0975 - 8887, 2014.

[7] A. A. Wieczorkowska, Z. W. Ra's and R. Lewis, "Multi-way Hierarchic Classification of Musical Instrument Sounds".

[8] S. Essid, G. Richard and. B. David, "Musical Instrument Recognition by Pairwise Classification Strategies," IEEE TRANSACTIONS ON AUDIO, SPEECH, AND LANGUAGE PROCESSING, Vols. VOL. 14, NO. 4, JULY 2006.

[9] S. Essid, G. Richard and B. David, "Efficient musical instrument recognition on solo performance music using basic features," in AES 25th International Conference, London, U.K., 2004.

[10] A. Eronen, "COMPARISON OF FEATURES FOR MUSICAL INSTRUMENT RECOGNITION," Tampere, Finland.

[11] D. M. Chandwadkar and M. S. Sutaone, "Selecting Proper Features and Classifiers for Accurate Identification of Musical Instruments," International Journal of Machine Learning and Computing, vol. 3, no. 2, April 2013.

[12] P. Herrera, G. Peeters and S. Dubnov, "Automatic Classification of Musical Instrument Sounds," Journal of New Music Research, vol. 32, 2003.

[13] A. Glowacz, W. Glowacz, and A. Glowacz, "Sound Recognition of Musical Instruments with Application of FFT and K NN Classifier with Cosine Distance".

[14] ISO/IEC 15938 (2002). Information Technology - Multimedia Content Description Interface. First Edition.

[15] Rabiner, L. \& Juang, B. (1993). Fundamentals of speech recognition. New York: Prentice-Hall.

[16] Dalibor Mitrovic, Matthias Zeppelzauer, and Horst Eidenberger," Analysis of the Data Quality of Audio Descriptions of Environmental Sounds", Journal of Universal Knowledge Management, vol. 1, no. 1 (2006).

[17] P. Shinde, V. Javeri and O. Kulkarni, "Musical Instrument Classification using Fractional Fourier Transform and KNN Classifier," International Journal of Science, Engineering and Technology Research (IJSETR), vol. 3, no. 5, May 2014.
[18] G. Agostini, M. Longari and E. Pollastri, "Musical instrument timbres classification with spectral features," in Proc. International Workshop Multimedia Signal Processing, Cannes, France, Oct. 2001.

[19] K. Jensen and J. Ampang, "Binary Decision Tree Classification of Musical Sound," in ICMC Proceedings, 1999.

[20] G. Mazarakis, P. Tzevelekos and G. Kouroupetr, "Musical Instrument Recognition and Classification Using Time Encoded Signal Processing and Fast Artificial Neural Networks".

[21] H. Fletcher, "Loudness, Pitch and Timber of Musical Tones and their Relations to the Intensity, the Frequency and the Overtone Structure," JASA, vol. 6/2,59-69.

[22] S. K. Banchhor and A. Khan, "Musical Instrument Recognition using Spectrogram and Autocorrelation," International Journal of Soft Computing and Engineering (IJSCE), ISSN: 2231-2307, vol. 2, no. 1, March 2012.

[23] Sarfaraz Masood; Shubham Gupta; Shadab Khan, "Novel approach for musical instrument identification using neural network", 2015 Annual IEEE India Conference (INDICON), ISSN: 2325-9418, March 2016.

[24] Mohammad Adeli; Jean Rouat; Sean Wood; Stéphane Molotchnikoff; Eric Plourde, "A Flexible Bio-Inspired Hierarchical Model for Analyzing Musical Timbre", IEEE/ACM Transactions on Audio, Speech, and Language Processing, ISSN: 2329-9304, Vol:24, Issue:5, May 2016.

[25] Yoonchang Han; Jaehun Kim; Kyogu Lee, ”Deep Convolutional Neural Networks for Predominant Instrument Recognition in Polyphonic Music", IEEE/ACM Transactions on Audio, Speech, and Language Processing, ISSN : 2329-9304,Volume: 25, Issue:1, Jan.2017.

[26] Shubham Bahre; Shrinivas P. Mahajan; Rohan T. Pillai, "Novel audio feature set for monophonic musical instrument classification”, 2017 International Conference on Recent Innovations in Signal Processing and Embedded Systems (RISE), ISBN:978-1-5090-4760-4, June 2018.

[27] Monica S. Nagawade, Varsha R. Ratnaparkhe, "Musical instrument identification using MFCC", 2017 2nd IEEE International Conference on Recent Trends in Electronics, Information \& Communication Technology (RTEICT), ISBN: 978-1-5090-3704-9, January 2018.

[28] Sushen R. Gulhane, Sanjay S. Badhe, Dr. Suresh D. Shirbahadurkar," Cepstral (MFCC) Feature and Spectral (Timbral) Features Analysis for Musical Instrument Sounds",2018, $2^{\text {nd }}$ IEEE Global International Conference on Wireless Computing and Networking(GCWCN-2018), ISBN-9781-5386-5201-5,23-24 Nov 2018.

[29] https://en.wikipedia.org/wiki/Self-organizing_map

[30] http://www.indian-heritage.org/music/inst1.htm 